\title{
Occult metastases: Real harm or false alarm?
}

\author{
Richard J. Cote, MD, FRCPath
}

See related article on page 551.
From the University of Southern California/Keck School of Medicine, Norris Comprehensive Cancer Center, Los Angeles, Calif.

Received for publication Oct 24, 2002; accepted for publication Nov 5, 2002.

Address for reprints: Richard J. Cote, MD, FRCPath, USC Norris Comprehensive Cancer Center, Department of Pathology, Room 2424, 1441 Eastlake Ave, Los Angeles, CA 90033 (E-mail: cote_r@norris. hsc.usc.edu).

J Thorac Cardiovasc Surg 2003;126:332-3

Copyright (C) 2003 by The American Association for Thoracic Surgery

$0022-5223 / 2003 \$ 30.00+0$

doi:10.1016/S0022-5223(02)73590-3

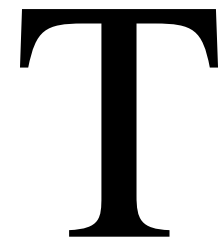

he most important factor predicting the outcome for patients with lung cancer (and indeed most solid tumors) is whether the tumor has spread locally, regionally, and/or systemically. It is well recognized that occult spread of tumor can occur, even in patients who have undergone complete removal of the primary tumor, and this phenomenon is the basis for the later development of overt metastases in these patients. Indeed, the possible presence of occult tumor dissemination is the rationale behind the use of systemic adjuvant chemotherapy in patients who have undergone definitive treatment of the primary tumor. Recognizing this, substantial efforts have been made to devise sensitive methods to detect occult regional and systemic spread of tumor. The central idea is that the detection of occult tumor might identify those patients at increased risk for recurrence and might thus affect the subsequent management of these patients, including the decision to administer adjuvant systemic therapy.

The article by Marchevsky and colleagues ${ }^{1}$ comes from a group long involved in the study and analysis of lung cancer and represents a substantial undertaking. The goal of this study was to determine the incidence and significance of finding previously undetected lymph node metastases (termed here "occult lymph node metastases") in patients with non-small cell lung carcinoma by using sensitive immunohistochemical procedures. The investigators examined a range of patients with non-small cell lung carcinoma, including those with node-negative (N0), N1, and N2 disease.

In the case of patients with $\mathrm{N} 2$ disease, no further metastases were detected by means of immunohistochemistry in lymph nodes, indicating that ultrasensitive detection methods might not provide useful additional information in these patients. In patients with $\mathrm{N} 1$ disease, 9 of 11 patients had tumor cells detected by means of immunohistochemistry, but none of these patients were upstaged to N2 disease. The authors suggest that detection of occult metastases with sensitive methodologies might not be useful in patients with node-positive lung cancer. This is perhaps not entirely surprising. Patients with node-positive lung cancer generally have a poor outcome, and detection of further occult disease might not be expected to have a major effect on the management of these patients.

This study also suggests that patients with occult lymph node metastases or those with microscopic lymph node involvement (as defined by tumor size in the lymph node of $\leq 2 \mathrm{~mm}$ [Nmi]) might have better outcomes than patients with overt $\mathrm{N} 1$ or $\mathrm{N} 2$ disease, the implication being that minimal lymph node involvement might identify a prognostically different subgroup of patients than those with overt lymph node involvement. This is an interesting and important notion and again is entirely expected because the extent of tumor involvement is well known to have a major effect on outcome. For example, in patients with lung cancer, those with N2 disease clearly do more poorly than those with $\mathrm{N} 1$ disease. In the case of breast carcinoma, it has been well documented that the number of involved axillary nodes is a highly significant predictor of outcome; patients with fewer positive nodes do far better than those with larger numbers of positive nodes. ${ }^{2,3}$ Thus we might expect that if the presence of minimal lymph node involvement (including occult metastases) is prognostically important, the effect on outcome might be less than for patients with a greater tumor burden (eg, more obvious involvement determined by using routine histology). 
If detection of occult metastasis has an effect on outcome, it might be expected to be most important in patients with node-negative (N0) disease. In this study 33 patients were initially classified as node negative, and a substantial minority (5 [15\%]) of these patients had occult metastasis detected by means of immunohistochemistry. These results are entirely consistent with other studies, and once again demonstrate that a proportion of patients with histologic node-negative disease will have tumor cells detected in their lymph nodes by means of more sensitive methods. ${ }^{4,5}$

The larger issue is the effect of occult metastases on outcome. In the present study ${ }^{1}$ the presence of occult lymph node metastases was not statistically significantly associated with a survival difference compared with cases that remained node negative after immunohistochemistry. However, this should not be interpreted to mean that the presence of occult lymph node metastases is not important. The number of node-negative patients in the present study was too small to have the power to draw conclusions, regarding the prognostic significance of occult lymph node metastases. Cohort size has been an issue with studies of occult lymph node metastases in a number of tumor systems, notably breast, lung, and colon cancer. ${ }^{4,6,7}$ Thus no conclusions should be drawn from the present study regarding the prognostic significance of occult metastases in patients with node-negative disease.

Several other studies with large numbers of patients have indicated that the presence of occult lymph node metastases in patients with node-negative lung cancer is a highly significant predictor of recurrence and survival, ${ }^{4,5,8}$ and the same is true for patients with other tumors as well. ${ }^{6,7,9} \mathrm{In}$ fact, the accumulating evidence is that occult regional (lymph node) metastasis might indeed be prognostically important in patients with node-negative lung cancer, nodenegative breast cancer, and other tumors. ${ }^{4,6,9}$

Although the present study ${ }^{1}$ is focused on the detection of occult regional (lymph node) metastases, there exist substantial efforts to detect occult systemic dissemination of tumor cells as well, through the testing of bone marrow and blood. These studies also indicate that the presence of occult tumor cells in the bone marrow identifies patients with lung, breast, and other tumors, who are at significantly increased risk for progression. ${ }^{4,6,9-13}$

The detection of occult metastases might help us to better identify patients with lung (and other) cancer who are at higher risk for development of metastatic disease and who would thus most benefit from systemic adjuvant therapy. Importantly, sensitive techniques to determine those patients who do and do not have detectable occult metastases might also identify patients with a highly favorable prognosis, who might thus not benefit from systemic treatment and for whom systemic treatment will only incur expense and side effects.

However, as pointed out by the present study, ${ }^{1}$ the utility and significance of detecting occult tumor cell dissemination remains controversial. To resolve these issues, the American College of Surgeons Oncology Group has instituted 2 large clinical trials. The Z40 trial in lung cancer and the Z10 trial in breast cancer will examine bone marrows and lymph nodes for the presence of occult metastases. These studies currently involve over 120 institutions, with expected accrual of over 1200 patients to the Z40 lung cancer study and over 3000 patients to the Z10 breast cancer study. If the clinical utility of the detection of occult metastases is confirmed by these large-scale multi-institutional clinical trials, it will have an important effect on the future management of lung cancer and other malignancies.

\section{References}

1. Marchevsky AM, Qiao J-H, Krajisnik S, Minocha JM, McKenna RJ. The prognostic significance of intranodal isolated tumor cells and micrometastases in patients with non-small cell carcinoma of the lung. J Thorac Cardiovasc Surg. 2003;126:551-7.

2. Fisher B, Slack N, Katrych D, Wolmark N. Ten year follow-up results of patients with carcinoma of the breast in a co-operative clinical trial evaluating surgical adjuvant chemotherapy. Surg Gynecol Obstet. $1975 ; 140: 528-34$

3. Nemoto T, Vana J, Bedwani RN, Baker HW, McGregor FH, Murphy GP. Management and survival of female breast cancer: results of a national survey by the American College of Surgeons. Cancer. 1980; 45:2917-24.

4. Pantel K, Cote RJ, Fodstad O. Detection and clinical importance of micrometastatic disease. J Natl Cancer Inst. 1999;91:1113-24.

5. Cote R, Hawes D, Chaiwun B, Beattie EJ. Detection of occult metastases in lung carcinomas: progress and implications for staging. J Surg Oncol. 1998;69:265-74.

6. Hawes D, Neville AM, Cote RJ. Occult metastases in patients with breast cancer. Ann Surg Oncol. 2001;8:60-3.

7. Cote RJ, Peterson HF, Chaiwun B, et al. Role of the immunohistochemical detection of lymph nodes metastases in the management of breast cancer. Lancet. 1999;354:896-900.

8. Kubuschok B, Passlick B, Izbicki JR, Thetter O, Pantel K. Disseminated tumor cells in lymph nodes as a determinant for survival in surgically resected non-small-cell lung cancer. J Clin Oncol. 1999;17: 19-24.

9. Chatterjee SJ, Hawes D, Taylor CR, Neville AM, Cote RJ. Occult metastases. In: Silberman H, Silberman AW, editors. Surgical oncology: multidisciplinary approach to difficult problems. New York (NY): Oxford University Press; 2002. p. 69-97.

10. Pantel K, Izbicki J, Passlick B, et al. Frequency and prognostic significance of isolated tumour cells in bone marrow of patients with non-small-cell lung cancer without overt metastases. Lancet. 1996; 347:649-53.

11. Cote RJ, Rosen PP, Lesser ML, Old LJ, Osborne MP. Prediction of early relapse in patients with operable breast cancer by detection of occult bone marrow micrometastasis. J Clin Oncol. 1991;9:1749-56.

12. Braun S, Pantel K, Muller P, et al. Cytokeratin-positive cells in the bone marrow and survival of patients with stage I, II, or III breast cancer. $N$ Engl J Med. 2000;342:525-33.

13. Cote RJ, Beattie EJ, Chaiwun B, et al. Detection of occult bone marrow micrometastases in patients with operable lung carcinoma. Ann Surg. 1995;222:415-25. 